Esta revista forma parte del acervo de la Biblioteca Jurídica Virtual del Instituto de Investigaciones Jurídicas de la UNAM www.juridicas.unam.mx

http://biblio.juridicas.unam.mx

\title{
La observación electoral en México: de la democratización a la consolidación democrática
}

\section{Ciro Murayama*}

\section{Sumario:}

I. Antecedentes

II. 1994: de la sombra de la violencia al fin de la transición

III. 2000: la alternancia como prueba de ácido de la democracia

IV. 2006: elecciones competidas e impugnadas

V. 2012: segunda alternancia y la confirmación de la pluralidad política

VI. Los temas de la democracia, no de la transición

VII. A modo de conclusión

VIII. Fuentes consultadas

* Profesor en la Facultad de Economía de la UNAM. 
Esta revista forma parte del acervo de la Biblioteca Jurídica Virtual del Instituto de Investigaciones Jurídicas de la UNAM www.juridicas.unam.mx http://biblio.juridicas.unam.mx

\section{Resumen:}

El presente texto se propone analizar cómo han ido cambiando a lo largo de las últimas dos décadas las condiciones en que se realizan los procesos electorales en México, y cómo esa transformación ha impactado la relevancia y el contenido mismo de la observación electoral. La hipótesis central es que mientras México consiguió construir reglas e instituciones que hicieron viable la existencia de un sistema de partidos plural, fincado en el respeto al voto, los temas de la observación electoral se movieron hacia aquellos asuntos que son problemas consustanciales a todo régimen democrático, como son, el asunto de la relación entre dinero y política, el acceso a los medios de comunicación y la calidad de los propios partidos políticos. Así, la observación electoral, que tradicionalmente se ha impulsado en aquellos países y contextos donde está en cuestión la posibilidad de ejercer un derecho político fundamental, como es el sufragio libre, en México ha dejado de ser una necesidad, de tal suerte que hoy más que de observación puede hablarse de una agenda de investigación sobre la vida democrática del país, similar a la que existente en el resto del mundo democrático.

Palabras clave: transición, democracia, alternancia, pluralidad política. 


\section{Antecedentes}

México vivió prácticamente todo el siglo XX bajo un sistema político dominado por un solo partido, el Revolucionario Institucional (PRI). Si bien las elecciones se celebraron de manera sistemática tal cual está definido en la Constitución Política de 1917, los cierto es que el sistema de "partido hegemónico" en los hechos minimizaba la competencia política y los procesos electorales eran un ritual con perdedores y ganadores conocidos de antemano. La máxima de que "el resultado es la única incertidumbre legítima en democracia" no se cumplía en México porque el país no era una democracia. Conviene señalar, no obstante, que México no vivió, tampoco, bajo una dictadura como sí ocurrió con múltiples naciones latinoamericanas en distintos momentos del siglo pasado.

La legitimidad del régimen político mexicano provenía de sus raíces históricas (la Revolución de 1910-1917), de su política de masas y capacidad de incorporación de las demandas y sectores populares ${ }^{2} \mathrm{y}$, también, porque México vivió un periodo largo de desarrollo económico que se prolongó desde los años treinta hasta entrados los años ochenta. ${ }^{3}$

El que en México no existiera una dictadura no implica que no llegaran a ocurrir episodios de extremo autoritarismo gubernamental. Es el caso, sin lugar a dudas, de la represión contra el movimiento estudiantil de 1968, que terminó con una matanza en la Plaza de las Tres Culturas de Tlatelolco. El movimiento estudiantil surgió en una sociedad que crecía económicamente, que se urbanizaba y veía emerger a nuevas clases medias. Los hijos del llamado "milagro mexicano" fueron los protagonistas del reclamo democrático de $1968 .^{4}$

En la década de los años setenta, la movilización política contra el régimen se intensificó, como lo muestra el auge del sindicalismo universitario en aquel momento, del sindicalismo independiente en

\footnotetext{
1 Sartori, Giovanni, Partidos y sistemas de partidos, Madrid, Alianza, 1980.

2 Córdova, Arnaldo, La política de masas del cardenismo, México, Era, 1974.

3 Moreno-Brid, Juan Carlos y Ros, Jaime, Desarrollo y crecimiento en la economía mexicana. Una perspectiva histórica, México, Fondo de Cultura Económica, 2011.

4 Aguilar Camín, Héctor, Después del milagro, México, Cal y Arena, 1991.
} 
Esta revista forma parte del acervo de la Biblioteca Jurídica Virtual del Instituto de Investigaciones Jurídicas de la UNAM

sectores clave - como los electricistas $-{ }^{5}$ o el resurgimiento de organizaciones agrícolas y de colonos. En el extremo del descontento político, se dio incluso el surgimiento de distintos grupos armados que, tras la represión del 68, estuvieron convencidos de que el único cambio viable habría de darse de forma violenta. ${ }^{6}$ De forma paradójica, como han señalado Becerra, Salazar y Woldenberg, ${ }^{7}$ en medio de esa crispación política real las elecciones formales transcurrían bajo la apariencia de un país donde reinaba la unanimidad, pues a las votaciones presidenciales de 1976 se postuló un solo candidato que obtuvo, por consiguiente, el cien por ciento de los sufragios. Así, la vía institucional corría en paralelo, separada y al margen, de la vida política real y viceversa. Fue esa situación la que dio lugar a la reforma política de 1977 que reconoció a los partidos políticos como entidades de interés público en la Constitución, permitió la incorporación de la izquierda - en especial del Partido Comunista Mexicano- a la arena electoral, y abrió nuevos cauces para la representación política de las minorías en la Cámara de Diputados.

En los años setenta la economía mexicana mostraba importantes desequilibrios - en el sector público y en el sector externo- que comenzaban a lastrar su capacidad de crecimiento, pero el descubrimiento de importantes reservas de petróleo en el Golfo de México y la subida de los precios internacionales del combustible dieron al país una ingente cantidad de recursos adicionales que permitieron, si no resolver los problemas estructurales de la economía mexicana, sí posponer su manifestación.

1982 fue año de cambio de gobierno y también de la irrupción de la llamada "crisis de la deuda" que a su vez propició lo que la Comisión Económica para América Latina y el Caribe (CEPAL) de las Naciones Unidas definió como la "década perdida". Si bien las elecciones transcurrieron en el formato tradicional, con un ganador que se conocía de antemano, el PRI, la novedad fue que a diferencia de las anteriores, de 1976, esta vez concurrieron siete candidatos distintos. El abanderado del PRI, Miguel de la Madrid, obtuvo siete de cada diez votos

5 Trejo Delarbre, Raúl, Crónica del sindicalismo en México (1976-1988), México, Siglo XXI-UNAM, 1990.

6 Castellanos, Laura, México armado, 1943-1981, México, Era, 2007.

7 Becerra, Ricardo et al., La mecánica del cambio político en México, México, Cal y Arena, 2000. 
(68.43\%) y su partido ganó en 299 de los 300 distritos electorales y obtuvo los 64 escaños en el Senado. ${ }^{8}$

La política económica del nuevo gobierno puso énfasis en el pago de la deuda externa, lo que implicó importantes recortes a la inversión pública y al gasto social, ${ }^{9}$ impactando negativamente sobre el crecimiento, la distribución del ingreso y el bienestar. El mal desempeño económico, traducido en pérdida de poder adquisitivo de los salarios y estancamiento en la creación de empleo formal, comenzó a producir un descontento de índole económico hacia un régimen político que había contado entre sus activos con la capacidad de generar movilidad social y expectativas de mejora económica para importantes franjas poblacionales.

Las elecciones de 1988 significaron una elocuente prueba a la legitimidad del régimen y de su política económica. Para entonces, había avanzado un proceso de unificación al seno de la izquierda mexicana que confluyó en el Partido Mexicano Socialista (PMS) tras haber creado, en 1981, el Partido Socialista Unificado de México (PSUM). En el otro flanco político, el Partido Acción Nacional (PAN) se había nutrido con la llegada a sus filas de distintos líderes empresariales, provenientes sobre todo del norte del país. En el PRI se produjo una escisión de la corriente democrática encabezada por Cuauhtémoc Cárdenas - hijo del general Lázaro Cárdenas- y Porfirio Muñoz Ledo - quien había sido presidente del PRI-, inconformes con las decisiones de política económica seguidas por el gobierno, así como con el "dedazo" - la designación del candidato presidencial del partido por su antecesor-.

Cárdenas fue postulado por varios partidos pequeños, que incluso habían jugado el papel de comparsas del régimen (el Popular Socialista, el Auténtico de la Revolución Mexicana, el Frente Cardenista de Reconstrucción Nacional) y esa candidatura rápidamente fue sumando importantes apoyos, incluso desde la izquierda, a grado tal que el abanderado del PMS, Heberto Castillo, declinó su candidatura a favor de Cárdenas. Así, los cuatro partidos que conformaron el Frente Democrático Nacional acudieron a las elecciones con un mismo candi-

\footnotetext{
8 Woldenberg, José, La transición democrática en México, México, El Colegio de México, 2012, p. 37.

9 Murayama, Ciro, La economía política de la educación superior, México, ANUIES, 2009.
} 
Esta revista forma parte del acervo de la Biblioteca Jurídica Virtual del Instituto de Investigaciones Jurídicas de la UNAM

dato; el PRI, por su parte, había postulado a Carlos Salinas de Gortari y el PAN al empresario Manuel Clouthier.

Aquellas elecciones ocurrieron en un país monocolor en términos de gobierno y de representación. Por ejemplo, el PRI tenía mayoría en la Cámara de Diputados, el cien por ciento de los senadores, el total de los gobernadores y mayoría en todos de los congresos locales, además de, por supuesto, la Presidencia. La Comisión Federal Electoral, era presidida por el secretario de gobernación, designado por el presidente de la República, y al seno de dicha comisión un solo partido, el PRI, tenía la mayoría de los votos para tomar las decisiones sobre la organización de los comicios.

Las elecciones del 6 de julio de 1988 fueron cuestionadas por todos los partidos y candidatos de la oposición. La noche de la votación, desde el gobierno, que controlaba la Comisión Federal Electoral se anunció la "caída del sistema" para no hacer públicos los resultados y pronto se extendió una ola de impugnación. Los resultados oficiales atribuyeron $50.85 \%$ de los votos al candidato del PRI, $30.8 \%$ a Cárdenas y $17.07 \%$ a Clouthier.

Las elecciones de 1988 pusieron dos nuevas sobre la realidad mexicana, una positiva y la otra negativa. La primera es que la pluralidad política del país se expresaba de forma contundente, que la sociedad mexicana no cabía en una sola fuerza política y, la segunda, que ni las normas ni las instituciones electorales existentes podían asegurar la coexistencia política del país.

Fue en esos años en que se empezó a plantear, en el caso de México, la idea de la transición a la democracia. El Instituto de Estudios para la Transición Democrática, definió en ese entonces en un documento titulado precisamente Para una transición democrática: ${ }^{10}$

Los resultados de la elección más allá del litigio en torno a las cifras oficiales que habían sido impugnadas por los partidos de oposición, mismos que muestran a un país que no puede ser alineado en el monolitismo como en el pasado. Los ciudadanos buscan, y encuentran, discursos, organizaciones, plataformas y propuestas distintas y ellas adquieren cauces a través de una amplia diversidad de partidos y agrupaciones sociales. Estamos ante un pluralismo que demanda pensar al país con otras fórmu-

${ }_{10}$ Los responsables de ese pronunciamiento del IETD fueron: Rolando Cordera Campos, Arnaldo Córdova, Gilberto Guevara Niebla, Pablo Pascual Moncayo, Adolfo Sánchez Rebolledo, Raúl Trejo Delarbre, José Woldenberg. 
las... Estamos ante una situación prevista y deseada por distintos partidos y agrupaciones políticas así como por intelectuales y organizaciones sociales pero a diferencia del pasado inmediato hoy todo parece indicar que la aspiración de una transición democrática cuenta con el respaldo activo de franjas importantes de la población. ${ }^{11}$

Tras las elecciones, Cuauhtémoc Cárdenas llamó a fundar un nuevo partido político nacional (el actual Partido de la Revolución Democrática), y desde el gobierno se entendió la necesidad de realizar una reforma electoral que pudiera dar confianza a los procesos electorales sucesivos. Así, al inicio de la década de los noventa se crea a través de una reforma constitucional el Instituto Federal Electoral (IFE), un "organismo profesional", "autónomo en sus decisiones", y cuyos principios rectores serían "la certeza, la imparcialidad y la objetividad"; junto con la creación del IFE, se dispuso la construcción, desde cero, de un padrón electoral confiable. ${ }^{12}$ Asimismo, se creó un Tribunal Federal Electoral para hacerse cargo de las impugnaciones en los comicios federales.

A fines de los años ochenta, en 1989, se da la primera alternancia en una gubernatura en México desde el inicio del régimen posrevolucionario, con el triunfo del candidato del PAN en Baja California.

En 1991, se celebran elecciones intermedias y el PRI recupera su caudal de votación, al obtener el $61.43 \%$ de los votos con lo que alcanzó 320 de los 500 asientos en la Cámara de Diputados. ${ }^{13}$

En los años subsecuentes, con la nueva mayoría que le dieron las elecciones, el PRI impulsó un conjunto de importantes reformas que terminaron por sellar la nueva institucionalidad de la conducción económica de México, entre ellas, la firma del Tratado de Libre Comercio con Estados Unidos y Canadá, la autonomía del Banco de México, así como la reforma al artículo 27 constitucional que regulaba la propiedad ejidal de la tierra agrícola, además de que se avanzó en el proceso de privatización de empresas públicas - con excepción de las de energía-. Sin embargo, la conflictividad política y los descalabros económicos harían su (re)aparición en 1994, el año de cambio de gobierno.

11 Instituto de Estudios para la Transición Democrática, A. C. (IETD), Para una transición democrática, México, IETD, mimeo, 1989.

12 Becerra, Ricardo et al., La mecánica..., cit., p. 240.

13 Woldenberg, José, La transición..., cit., p. 76. 
Esta revista forma parte del acervo de la Biblioteca Jurídica Virtual del Instituto de Investigaciones Jurídicas de la UNAM

\section{1994: de la sombra de la violencia al fin de la transición}

El primer día de 1994 se produjo una insurrección armada en el sureño estado de Chiapas, atacando cuarteles militares y varios edificios de gobierno en distintos municipios de la entidad. El Ejército Zapatista de Liberación Nacional (EZLN) declaró la guerra al gobierno de México en la primera declaración de la Selva Lacandona. A unos días del alzamiento, el gobierno de México decretó un alto al fuego de forma unilateral y convocó al diálogo al EZLN. Asimismo, el gobierno nombró un comisionado para la paz en Chiapas (el ex regente del gobierno de la Ciudad de México y entonces secretario de relaciones exteriores, Manuel Camacho Solís, hoy senador por el opositor Partido de la Revolución Democrática) y sustituyó al secretario de gobernación, nombrando al prestigiado investigador Jorge Carpizo (quien además de haber sido rector de la UNAM fue primer el presidente de la Comisión Nacional de los Derechos Humanos).

Los partidos políticos, por su parte, el 27 de enero de 1994 firmaron un conjunto de compromisos para asegurar el desarrollo de elecciones imparciales y creíbles como respuesta desde la política al violento llamado de las armas. Fue la primera vez, que el PRD se sumó al acuerdo político multipartidista, por lo que puede decirse que la reforma de 1994 fue la primera en la que participaron las tres principales fuerzas políticas del país. El núcleo de aquella reforma es el siguiente:

El Congreso de la Unión modificó el artículo 41 constitucional para establecer que la organización de las elecciones, no obstante ser considerada una función estatal, se realizará a través de un organismo público y autónomo con la concurrencia de los poderes ejecutivo y legislativo, los partidos y los ciudadanos. Con esta reforma, se refrendaba en el cuerpo constitucional la autonomía del Instituto Federal Electoral y se contemplaba directamente, a nivel constitucional, que 'ciudadanos' elegidos por el Congreso de la Unión serían corresponsables de la organización electoral. ${ }^{14}$

Además de introducir la figura de los consejeros ciudadanos al órgano de dirección y decisión de la autoridad electoral, los partidos políticos

14 Becerra, Ricardo et al., La mecánica..., cit., p. 326. 
Esta revista forma parte del acervo de la Biblioteca Jurídica Virtual del Instituto de Investigaciones Jurídicas de la UNAM

perdieron su voto en el mismo, de tal suerte que sólo quedaron once votos en el Consejo General del IFE, de los cuales uno sería del presidente (el secretario de gobernación), cuatro del Poder Legislativo (y de al menos dos fuerzas políticas diferentes) y seis de los consejeros ciudadanos.

El cambio en el diseño del órgano encargado de la organización de las elecciones entre una elección presidencial y otra, entre 1988 y 1994, es elocuente como se ve en la tabla 1.

Tabla 1

Comparación de la conformación de la autoridad electoral federal en México, 1988 y 1994

\begin{tabular}{|c|c|}
\hline Comisión Federal Electoral (1988) & $\begin{array}{c}\text { Consejo General del Instituto Federal } \\
\text { Electoral (1994) }\end{array}$ \\
\hline $\begin{array}{l}\text { - Secretario de gobernación (presidente) } \\
\text { - } 1 \text { senador } \\
\text { - } 1 \text { diputado } \\
\text { - Representación de los partidos (propor- } \\
\text { cional a su votación) } \\
\text { - PRI: } 16 \\
\text { - PAN: } 5 \\
\text { - PFCRN: } 1 \\
\text { - PPS: } 1 \\
\text { - PARM: } 1 \\
\text { - PMS: } 2 \\
\text { - PDM: } 1 \\
\text { - PRT: } 1 \\
\text { Total: } 31\end{array}$ & $\begin{array}{l}\text { - Secretario de gobernación (presidente, } \\
\text { con voz y voto) } \\
\text { - Director general } \\
\text { - Secretario del Consejo } \\
\text { - Dos consejeros de la Cámara de Sena- } \\
\text { dores (de mayoría y primera minoría, } \\
\text { respectivamente, con voz y voto) } \\
\text { - Dos consejeros de la Cámara de Diputa- } \\
\text { dos (de mayoría y primera minoría, con } \\
\text { voz y voto) } \\
\text { - Seis consejeros ciudadanos (con voz y } \\
\text { voto) } \\
\text { - Un representante de cada partido po- } \\
\text { lítico nacional (PAN, PRI, PRD, PPS, } \\
\text { PFCRN, PARM, PDM, PT, PVEM) }\end{array}$ \\
\hline
\end{tabular}

Fuente: elaboración propia a partir de Becerra et al., La mecánica del cambio político en México, cit.

Además, los consejeros ciudadanos estarían presentes en todos los órganos desconcentrados del IFE, esto es, en los 32 consejos locales - uno por entidad federativa - y en los 300 consejos distritales - uno por cada distrito electoral federal- habría seis votos de consejeros ciudadanos, más uno del vocal ejecutivo del IFE.

Por otra parte, a partir de la creación del IFE también se inició con la práctica de conformar las mesas directivas de casilla a las que acuden los ciudadanos a depositar su voto a través de un proceso de sor- 
Esta revista forma parte del acervo de la Biblioteca Jurídica Virtual del Instituto de Investigaciones Jurídicas de la UNAM

teo entre los propios ciudadanos de la sección electoral. ${ }^{15}$ Como se ve, las reformas iniciales para recuperar la confianza en los procesos electorales se enfocaron a incrementar los mecanismos de control e imparcialidad en la tarea de organización de los comicios. El objetivo es que efectivamente votaran los ciudadanos que tenían derecho para hacerlo, sin exclusiones ni inclusiones arbitrarias, para lo cual se dispuso de la confección de un nuevo padrón, la inclusión de consejeros ciudadanos en toda la estructura organizativa del IFE, así como en depositar la tarea de recibir y contar los votos en ciudadanos designados por sorteo y no por su afiliación partidista. Es evidente, entonces, que la preocupación a la que atendía la reforma es que el voto se emitiera y se contara con independencia.

De esta forma se reforzaba la confianza en la autoridad electoral en un momento marcado por la incertidumbre política y la sombra ominosa de la violencia.

El 23 de marzo de 1994, mientras realizaba una gira de campaña el candidato presidencial del Partido Revolucionario Institucional, Luis Donaldo Colosio, fue asesinado a tiros en Tijuana, Baja California. Con este acto, "el país entero entró de nuevo en una confusión abrumadora y encargó otra cara de la violencia que parece querer entronizarse en la vida política desde el alzamiento chiapaneco". ${ }^{16}$

En ese entonces, el Instituto de Estudios para la Transición Democrática señaló:

Vivimos el tránsito a un sistema de partidos digno de tal nombre, a la vez que se mantienen muchos de los rasgos y mecanismos del pasado monopartidista. El contexto de esa mezcla de proceso y rezagos, está determinado por un ambiente en el que la violencia y la inseguridad, están exigiendo dosis cada vez más altas de responsabilidad. La violencia y la inseguridad pueden minar a la sociedad y al Estado, por lo que se requieren acciones estatales, con un fuerte apoyo de la sociedad, capaces de contribuir a la edificación de un sistema democrático. ${ }^{17}$

15 Ibidem, p. 254.

16 Cordera, Rolando, Crónicas de la adversidad, México, Cal y Arena, 1999.

17 “En busca de la normalidad democrática, ¿qué se juega en las elecciones?", firmado por Rolando Cordera Campos, Mauricio Merino, Ciro Murayama, Pablo Pascual Moncayo, Jacqueline Peschard, Enrique Provencio, Luis Salazar, Adolfo Sánchez Rebolledo, Raúl Trejo Delarbre y José Woldenberg. Dicho documento se puede consultar en Pascual Moncayo, Pablo, Las elecciones de 1994, México, Cal y Arena, 1995. 
Y en efecto los acuerdos entre los actores políticos más relevantes permitieron tener un proceso electoral nutrido de novedades democráticas, como fueron los hechos, sin precedentes, de que los tres principales candidatos a la Presidencia de la República (Ernesto Zedillo del PRI; Diego Fernández de Cevallos del PAN, y Cuauhtémoc Cárdenas del PRD) sostuvieran el primer debate televisado en la historia de México, o la suspensión de las campañas de comunicación social del gobierno veinte días antes de la jornada electoral.

Otra novedad de la elección de 1994 es que se permitió, por vez primera, la participación de observadores electorales - figura que se había incorporado a la ley desde 1993- y de visitantes extranjeros. En el primer caso se estableció que los observadores podrían participar "de los actos de preparación y desarrollo del proceso electoral, así como de los que se llevaran a cabo el día de la jornada electoral", y que la observación podría efectuarse a título individual o de agrupaciones, y se puntualizó que las conclusiones de los observadores no tendrían "efectos jurídicos" ${ }^{18}$ Por otra parte, el abrir la figura de los "visitantes extranjeros" significó un cambio en la disposición del Estado mexicano a la observación electoral externa, pues hasta entonces había sido renuente a que misiones externas acudieran a verificar el desarrollo de los comicios.

A partir de 1994 la observación electoral cobró carta de naturalidad en las elecciones mexicanas y desde ese entonces las Naciones Unidas han jugado un papel importante en dicha tarea. Lo que evidencia la disposición del sistema electoral mexicano a la observación electoral es que desde 1994 "la ONU recibió la solicitud de las autoridades mexicanas para apoyar las actividades de asesoría técnica, capacitación y administración de los recursos para los observadores electorales", ${ }^{19}$ así como el hecho de que es el propio Estado mexicano quien financia la observación electoral que se hace en el país, cosa que no ocurre en otra nación del mundo.

En 1994 se constituyó un fondo para la observación electoral de 50 millones de pesos. Ante el IFE se acreditaron 251 organizaciones de observadores y un total de 86620 observadores; de ellos 10 organizaciones recibieron recursos del fondo, así como 30000 observadores.

18 Becerra, Ricardo et al., La mecánica..., cit., pp. 329 y 330.

19 Programa de Naciones Unidas para el Desarrollo, Propuesta técnica de observación electoral, México, 2012. 
Esta revista forma parte del acervo de la Biblioteca Jurídica Virtual del Instituto de Investigaciones Jurídicas de la UNAM

Como ha señalado el PNUD en 2012, en aquel año la asistencia de Naciones Unidas se dio:

bajo el objetivo fundamental de generar confianza de la sociedad en las instituciones electorales y en la organización de los comicios. Por lo tanto, la asistencia técnica y los programas de información dirigidos a los observadores estuvieron centrados en la jornada electoral y en los días previos a la misma.

Como puede apreciarse, el hecho de que el grueso de la observación se desplegara el día de la jornada electoral demuestra que la preocupación central en ese entonces radicaba en que las casillas operaran conforme a lo establecido en la ley, que votaran los ciudadanos que correspondían a cada casilla debidamente identificados, que el voto se emitiera en secreto y por ello en libertad, que la casilla se instalara en el lugar previsto y por los funcionarios designados para ello, etcétera. De forma natural, tras la experiencia de las elecciones de 1988, la agenda de la observación en 1994 se concentró básicamente en el día de la jornada electoral y se refirió al procedimiento del sufragio.

Valga un apunte sobre las asociaciones que participaron en la observación electoral, que además de incluir a organismos empresariales, como la COPARMEX, fueron

las llamadas organizaciones cívicas [que] se nuclearon y actuaron durante varios años alrededor de la limpieza electoral, de la generación de 'nuevas formas de hacer política'... El discurso de este sector tiende a identificar sociedad civil con redes de ONG... esta autopercepción de la sociedad civil como red de organizaciones ciudadanas parece en cambio borronear los límites entre sociedad civil y sociedad política. De allí su tensa y ambivalente relación con los partidos políticos, su no siempre clara relación con el marco legal e institucional, el encauzamiento de varias de ellas por la vía de las llamadas agrupaciones políticas o la identificación casi exclusiva con algunas figuras individuales (política de notables). ${ }^{20}$

En las elecciones del 21 de agosto de 1994 acudió a votar el 78\% de los ciudadanos empadronados, el candidato del PRI alcanzó el 50.13\%

20 Rabotnikof, Nora, "Dos conceptos de sociedad civil”, en Salazar, L. (coord.), México 2000. Alternancia y transición a la democracia, México, Cal y Arena, 2001. 
Esta revista forma parte del acervo de la Biblioteca Jurídica Virtual del Instituto de Investigaciones Jurídicas de la UNAM

de los sufragios, el del PAN el 26.69\% y el del PRD el $17.07 \%$. En la Cámara de Diputados el PRI obtuvo el 60\% de los escaños, el PAN 23.8\%, el PRD 16.65\% y el PT 2.67\%; en la Cámara de Senadores al PRI correspondieron 85 de 128 senadurías, al PAN 25 y al PRD 8. ${ }^{21}$

En ese entonces

agrupaciones distintas de observadores, canales de televisión, la COPARMEX, diferentes partidos políticos, realizaron el mismo 21 de agosto ejercicios muestrales de cómputo de los votos, y los resultados de todos y cada uno de ellos se mueven en rangos muy similares. ${ }^{22}$

Desde otro espacio de la opinión pública, el importante escritor e intelectual mexicano, Octavio Paz escribió:

El testimonio de los observadores nacionales es inequívoco: ninguna de esas irregularidades aisladas o en su conjunto pueden alterar de manera significativa la distribución del voto. Las cifras y los porcentajes que conocemos son confiables. ${ }^{23}$

En el balance del Instituto de Estudios para la Transición Democrática de aquella elección, puede leerse:

El 21 de agosto asistimos a los comicios más concurridos y vigilados de la historia nacional. Cerca del 78\% de los ciudadanos empadronados concurrieron pacíficamente a las urnas para expresar con su voto sus preferencias políticas, dentro de un proceso caracterizado por la ausencia de incidentes o problemas de gravedad... los resultados electorales hablan de una situación de pluralismo y competencia política crecientes y consolidadas. Hablan, por ende, de que no puede haber vuelta atrás a los tiempos de partido casi único porque cerca de la mitad de los electores votaron por otras opciones. Y hablan también de que la transición mexicana a la democracia tendrá que seguirse entendiendo como un proceso difícil y complicado de reformas, negociaciones y acuerdos, y no como consecuencia de una elección o de un derrumbe institucional, pues nos guste o no, el partido oficial cuenta, por su parte, con el apoyo de la mitad de los votantes. $\mathrm{Ni}$

\footnotetext{
21 Becerra, Ricardo et al., La mecánica..., cit., pp. 355 y ss.

22 Woldenberg, José, Violencia y política, México, Cal y Arena, 1995, p. 222.

23 Paz, Octavio, "Doble mandato", Vuelta, México, núm. 215, octubre de 1994.
} 
Esta revista forma parte del acervo de la Biblioteca Jurídica Virtual del Instituto de Investigaciones Jurídicas de la UNAM

regreso al pasado autoritario ni transición instantánea a la democracia: tal es la primera lección de los comicios del 21 de agosto. ${ }^{24}$

Ahora bien, el reconocimiento de que los comicios habían sido limpios, en el sentido de que los sufragios se contaron y se respetaron, no impidió identificar que en las elecciones en México había unas condiciones de competencia muy desiguales. En las semanas posteriores a la elección, en septiembre de 1994, el IETD subrayó que

el país está logrando una base firme para asentar una legitimidad propiamente democrática, es decir, para que los votos cuenten y se cuenten adecuadamente. No obstante, sería por lo menos ingenuo reducir la construcción de una democracia plena a esta dimensión sin duda necesaria pero insuficiente,

y llamaba a una reforma electoral "en un futuro próximo para otorgar una autonomía plena al Instituto Federal Electoral y para promover verdadera equidad en las contiendas electorales". ${ }^{25}$

Por otra parte, un análisis de los gastos de campaña de 1994, realizado por una comisión de consejeros ciudadanos del IFE, concluyó que el 71.4\% de todo el dinero erogado correspondía al PRI. ${ }^{26}$

Tras las elecciones de 1994, en 1996 se aprobó una importante reforma constitucional en materia electoral que, entre otros temas, posibilitó: 1) la plena autonomía del Instituto Federal Electoral; 2) la creación del Tribunal Electoral del Poder Judicial de la Federación como última instancia en la soluciones de controversias electorales en el país; 3) la ampliación de los derechos políticos de los habitantes de la capital del país, quienes a partir de 1997 eligieron al jefe de gobierno de la Ciudad de México y a partir del año 2000 a los jefes de cada una de las 16 delegaciones políticas; 4) la edificación de novedosas reglas de la competencia electoral.

Sobre este último punto, la reforma estableció que: a) el financiamiento público sería predominante sobre el privado, que se distribuiría siguiendo un criterio de equidad — no de igualdad-, y que en años

24 Documento "Después de las elecciones", en Pascual Moncayo, Pablo, Las elecciones..., cit.

25 Idem.

${ }^{26}$ Becerra, Ricardo et al., La mecánica..., cit., p. 371. 
de campaña el monto de recursos públicos destinado a los partidos se duplicaría; $b$ ) se definieron en la ley las modalidades de financiamiento privado - aportaciones de militantes, donaciones de simpatizantes y rendimientos financieros - y se establecieron límites a los montos de contribuciones privadas; $c$ ) se eliminó la posibilidad de que los poderes públicos, las empresas mercantiles, las iglesias y sus ministros, así como personas del extranjero, hicieran aportaciones a los partidos; d) se especificó la manera en que la autoridad electoral fijaría el límite máximo de gastos por tipo de candidatura en cada elección y se estableció que sólo los partidos y ningún tercero podría comprar anuncios en radio y televisión para influir en la decisión de los electores, y e) por primera vez se contó con un auténtico sistema de fiscalización sobre los ingresos y egresos de los partidos políticos, creando para ello una comisión ad hoc del Consejo General del Instituto Federal Electoral.

En particular, se fijaron criterios de reparto del financiamiento entre los partidos: el 30\% del total se divide en partes iguales entre todos los partidos y el otro $70 \%$ se distribuye según la votación alcanzada en la última elección federal.

Gracias a esas disposiciones, y después de décadas de una competencia electoral más que asimétrica entre el partido del gobierno y el resto de opciones políticas, el financiamiento público total de que dispusieron los partidos se multiplicó cinco veces en términos reales en 1997 - la primera elección después de la reforma - frente a lo que dispusieron en los comicios federales previos, los de 1994. Además, el reparto fue mucho más parejo: por ejemplo para la elección presidencial de 1994, el Partido Revolucionario Institucional (PRI) recibió el 53\% del financiamiento público, el Partido Acción Nacional (PAN) el 16\%, el Partido de la Revolución Democrática (PRD) el 9\%, y 2\% el Partido del Trabajo y el Partido Verde respectivamente. Es decir, gracias a la reforma electoral de 1996 se consiguió anular la enorme disparidad en el acceso a los recursos que había caracterizado al sistema político mexicano durante buena parte del siglo XX.

Los efectos positivos de la reforma sobre el sistema plural de representación son elocuentes. Puede preguntarse si los resultados electorales de las elecciones que han ocurrido desde entonces hubieran sido posibles sin equilibrar los recursos económicos de los partidos. La introducción de un financiamiento público predominante y de criterios de equidad en el reparto, a partir del proceso electoral de 1997, se tra- 
Esta revista forma parte del acervo de la Biblioteca Jurídica Virtual del Instituto de Investigaciones Jurídicas de la UNAM

dujo en una mayor competitividad que se refleja en los resultados de las votaciones; de hecho, cuando el PRI dejó de recibir por sí solo más recursos que los que recibían juntos los dos principales partidos de la oposición, también dejó de obtener más de la mitad de la votación nacional. Sin pretender establecer alguna regla determinista sobre el sentido de las preferencias ciudadanas (los votos de los partidos no dependen sólo de los recursos de que disponen o del tiempo de exposición en los medios de comunicación, sino de una enorme variedad de factores), lo cierto es que el fin de la hegemonía en el acceso a recursos también significó en México, el inicio de las elecciones de resultado incierto, como corresponde en democracia.

Las elecciones intermedias de 1997 arrojaron, entonces, una novedad mayor en la historia política de México, que fue la pérdida de la mayoría en la Cámara de Diputados para el partido del presidente de la República. Además de haber obtenido el 39.11\% de la votación nacional a diputados federales por mayoría relativa, el PRI consiguió el triunfo en 165 distritos en 1997, cuando tres años antes había ganado 273 distritos; en ese lapso el PAN pasó de ganar 20 a 64 distritos y el PRD de 7 a 70 distritos. ${ }^{27}$ Además el PRD consiguió la jefatura de gobierno de la Ciudad de México convirtiéndose en la primera entidad federativa gobernada por la izquierda.

La elección de 1997 si bien fue "intermedia" en términos federales, pues no se votó por la renovación del Ejecutivo Federal, fue muy trascendente por el hecho de que sí se eligió la jefatura de gobierno de la Ciudad de México que por esa única ocasión, de acuerdo a un artículo transitorio de la reforma constitucional de 1996, le tocó organizar al Instituto Federal Electoral —después la tarea recae en el Instituto Electoral del Distrito Federal-.

En las elecciones de 1997, ante el IFE se registraron 143 agrupaciones de observadores y 24391 observadores individuales, y se dispuso de un fondo de 12 millones de pesos que benefició a 24 organizaciones y a 19000 observadores. ${ }^{28}$

A la luz de la experiencia de las elecciones de 1997, organizadas por un IFE plenamente autónomo frente al Poder Ejecutivo, con múltiples candados de seguridad y vigilancia de los partidos políticos y los ciudadanos sobre cada fase del proceso electoral, puede cerrarse el perio-

27 Ibidem, p. 471.

28 Programa de Naciones Unidas para el Desarrollo, Propuesta..., cit. 
do de reformas políticas para la democratización de México que había comenzado 20 años antes, en 1977. Tal como concluyen Becerra, Salazar y Woldenberg: "Por la vía de las reformas negociadas, a través de la votación de miles de ciudadanos, mediante el fortalecimiento de los partidos políticos y de su capacidad competitiva, la historia democrática de México ha comenzado" ${ }^{29}$

\section{2000: la alternancia como prueba de ácido de la democracia}

Con la legislación electoral que había hecho posible que el presidente de la República y su partido perdieran el control de la Cámara de Diputados, por primera vez se organizaron unas elecciones presidenciales desde un Instituto Federal Electoral plenamente autónomo en el año 2000.

En aquellos comicios, se dio la alternancia en el Ejecutivo Federal, pero también se produjo por segunda vez consecutiva un gobierno dividido - al no obtener el partido del presidente mayoría - en la Cámara de Diputados y, por vez primera, en el Senado.

Vicente Fox, candidato opositor por el Partido Acción Nacional y el Partido Verde Ecologista de México, obtuvo el $42.52 \%$ de la votación; Francisco Labastida del PRI el $36.10 \%$ de los sufragios, y el candidato de las izquierdas, Cuauhtémoc Cárdenas el 16.64\%. En el Senado el PRI obtuvo 60 escaños; el PAN, 46; el PRD, 15; el PVEM 5; el PT y Convergencia 1 respectivamente. En la Cámara de Diputados las cifras fueron: PRI, 211; PAN, 206; PRD, 50; PVEM, 17; PT, 7; Convergencia, 4; Partido Sociedad Nacionalista, 3, y el Partido Alianza Social, $2 .^{30}$

En su momento, Luis Salazar definió:

Los cambios políticos que ha sufrido México en los últimos treinta años parecen haber culminado el 2 de julio de 2000 con el triunfo esperado pero aun así sorpresivo del candidato de la Alianza por el Cambio, Vicente Fox. Después de setenta y un años de predominio, el partido oficial, el

29 Becerra, Ricardo et al., La mecánica..., cit., pp. 481 y ss.

30 Woldenberg, José, La transición..., cit., p. 135. 
Esta revista forma parte del acervo de la Biblioteca Jurídica Virtual del Instituto de Investigaciones Jurídicas de la UNAM

\begin{abstract}
Partido Revolucionario Institucional (PRI), pudo ser derrotado pacíficamente en las urnas, y tanto el presidente como el candidato y la dirigencia de ese partido reconocieron inmediatamente su derrota. Contra lo que muchos decían, esperaban o temían, la alternancia a nivel del poder ejecutivo era ya, como se comprobó, una posibilidad efectiva garantizada por la legalidad y las instituciones encargadas de la organización, el cómputo y la calificación de los procesos electorales. ${ }^{31}$
\end{abstract}

Como consta en la Memoria del proceso electoral federal del año 2000: $:^{32}$

Fueron acreditados 23,364 observadores electorales en los Consejos Locales y 15,069 en los Consejos Distritales, lo que suma un total de 38,433 ciudadanos acreditados. De las acreditaciones aprobadas por los Consejos Locales, 22,883 correspondieron a agrupaciones de observadores y 481 se presentaron de manera individual. Por lo que se refiere a los Consejos Distritales, 11,953 acreditaciones se entregaron a ciudadanos miembros de agrupaciones de observadores y 3,116 de manera individual. La información sobre las acreditaciones de observadores, indica que las entidades federativas en donde se presentó el mayor número de éstas fueron el Estado de México con 4,249; el Distrito Federal, con 3,953; Jalisco, con 2,095; Puebla, con 1,176; y Michoacán con 1,728. Por otro lado, las entidades federativas en donde se registró el menor número de acreditaciones fueron Baja California Sur, con 211 observadores; Colima con 235; y Quintana Roo con 283.

En la elección de 2000 el fondo de recursos públicos de que se dispuso para entregar a quienes realizaron la observación electoral ascendió a 40 millones de pesos, y benefició a 38433 observadores y a 30 agrupaciones. $^{33}$

Como se aprecia, incluso las relevantes elecciones del año 2000, en las que se dieron las campañas más competidas de la historia hasta ese momento y en las que se abrió como nunca antes la posibilidad real de la alternancia en la presidencia - como finalmente ocurrió-, el número de observadores electorales disminuyó frente a los comicios

31 Salazar, Luis, México 2000: alternancia y transición a la democracia, México, Cal y Arena, 2001, p. 17.

32 Instituto Federal Electoral, Memoria del proceso electoral federal 2000, México, IFE, 2001.

33 Programa de Naciones Unidas para el Desarrollo, Propuesta..., cit. 
presidenciales previos. La reducción fue de 80000 observadores acreditados en 1994 a 30000 seis años después.

Los propios resultados de la elección del año 2000, inaugurando la alternancia y confirmando que ningún partido controlaría por sí mismo el Congreso, dieron pie a que las elecciones no fueran impugnadas políticamente. El reconocimiento del triunfo del candidato panista por sus adversarios permitió que desde la propia noche de la elección toda sombra de duda sobre la limpieza del proceso quedara diluida.

Sin embargo, en la historia política de las naciones no hay terminales finales y siempre surgen nuevos desafíos. El arribo de la democracia a la vida política mexicana trajo consigo una nueva agenda para el país que en el periodo de autoritarismo permaneció eclipsada o pospuesta. Entre los temas que han llegado para quedarse se encuentra la relación siempre conflictiva entre dinero y política, es decir, la manera en que se financian los actores políticos y la forma en que son fiscalizados por la autoridad. El tema es de la mayor importancia: la probidad en las conductas financieras de los partidos políticos gravita directamente sobre su credibilidad, y de la legitimidad de los partidos depende en última instancia el apoyo de la ciudadanía al sistema democrático. Que el dinero que fluye a la política surja de cauces conocidos, legales, transparentes, y que se utilice para los fines establecidos por la ley - sobre todo tratándose de recursos públicos- es una condición para la salud de las democracias.

En México, en la etapa final de la transición a la democracia se definió un marco para regular las condiciones de la competencia electoral que contribuyó a que las elecciones dejaran de ser un ritual con ganadores y perdedores predeterminados para llegar a ser un auténtico juego abierto donde la última palabra la tienen los ciudadanos. Existe un sistema de partidos, con distintas opciones reales, que producen fenómenos de alternancia en todos los niveles de gobierno, equilibrios y contrapesos de poder, así como un colorido mapa del gobierno y de la representación popular que refleja a la complejidad y pluralidad de la sociedad, que contrasta con el panorama monocolor de partido prácticamente único que perduró hasta entrada la última década del siglo XX.

Esa vida electoral, cada vez más competida, ha hecho aún más sensible el tema de la regulación del acceso de los partidos políticos a los recursos económicos y de fiscalización de los mismos. En particular, la denuncia, investigación y sanción a dos tramas de financiamiento 
Esta revista forma parte del acervo de la Biblioteca Jurídica Virtual del Instituto de Investigaciones Jurídicas de la UNAM

ilegal a propósito de las campañas a la Presidencia de la República en el año 2000, que involucraron a las dos fuerzas electorales de mayor arraigo en el país, el PRI y el PAN, hicieron que desde principios del siglo el control sobre los dineros de la contienda política sea prioridad en la atención pública y política mexicana. Los dos casos referidos desembocaron en multas que sin lugar a dudas pueden considerarse como históricas: 1000 millones de pesos al PRI (la más alta de las que se tenga noticia en los sistemas democráticos), y 545 millones a los partidos de la coalición Alianza por el Cambio, conformada por el PAN y el PVEM (que había llevado a la presidencia al titular del Ejecutivo en funciones). Ello demuestra que en México el marco legal e institucional para detectar y sancionar ilícitos en materia de financiamiento electoral funcionó, pero la misma experiencia de esos dos casos también arrojó lecciones sobre los límites e insuficiencias de las normas. ${ }^{34}$

Por otra parte, en las elecciones intermedias de 2003, que fueron organizadas por el mismo Consejo General del IFE que fue designado desde octubre de 1996, y que había contado con la experiencia de las elecciones de 1997 y 2000, la observación electoral disminuyó sensiblemente. Se registraron ante el IFE 12728 observadores y 157 organizaciones; de ellos, accedieron a recursos del fondo de recursos para la observación, que sumó 15 millones de pesos, 21 agrupaciones y 9758 observadores.

Esta reducción en el número de observadores es elocuente no sólo frente a la elección previa -2000 (con 38000 observadores) - sino respecto a la intermedia de 1997 —donde hubo 24000 observadores-. De esta forma, al menos cuantitativamente se puede apreciar una pérdida de centralidad de la tarea de la observación electoral en México en muy pocos años.

\section{2006: elecciones competidas e impugnadas}

Las elecciones de 2006 rompieron en buena parte con el dilatado y lento proceso de construcción de la credibilidad en los procedimientos, las normas y las instituciones electorales en México.

${ }^{34}$ Córdova, Lorenzo y Murayama, Ciro, Elecciones, dinero y corrupción. Pemexgate y Amigos de Fox, México, Cal y Arena, 2006. 
La decisión del presidente Vicente Fox de impedir que el principal aspirante opositor a la presidencia, Andrés Manuel López Obrador, entonces jefe de gobierno de la Ciudad de México, pudiera participar en las elecciones generó un clima de encono político que tuvo efectos duraderos. Con el caso conocido como "desafuero" a partir de un diferendo nimio por los límites de un terreno donde el gobierno de la ciudad empezó a construir una calle, habiendo una orden de un juez en sentido contrario, la pretensión del gobierno federal fue abrir un proceso penal contra López Obrador para que éste no pudiera ser candidato a la presidencia. Se llegó, incluso, a la votación en la Cámara de Diputados a favor del desafuero de López Obrador, mas la movilización política alrededor de la figura de quien había sido presidente nacional del PRD hizo que, finalmente, el gobierno rectificara su postura. Aún así, el daño estuvo hecho, la crispación política creció durante la campaña electoral de 2006 y el desenlace de los comicios puso en duda, una vez más, al sistema electoral mexicano.

La joven democracia mexicana se enfrentó en 2006 a la complicada situación de tener que procesar un resultado electoral de muy estrecho margen ( $0.56 \%$ de los votos) a favor del candidato del gobernante PAN, Felipe Calderón, para definir la Presidencia de la República. Ello, después de una larga campaña electoral caracterizada por el encono entre la administración federal encabezada por Vicente Fox y su partido, y el candidato de la izquierda Andrés Manuel López Obrador del PRD, quien se negó a reconocer la validez de los comicios. De manera paradójica, esta prueba de legitimidad sobre el sistema electoral mexicano sólo pudo tener lugar gracias a la existencia de un conjunto de reglas e instituciones que garantizan que la democracia sea un juego abierto, en el que compiten partidos y candidatos auténticos con posibilidades reales de ganar, y donde hay lugar para la incertidumbre acerca del resultado electoral. De esta forma, la votación de 2006, más que cuestionar si México tiene el grado democrático, es en sí misma una confirmación objetiva de que su vasta pluralidad política puede expresarse - y se expresa- a través de las elecciones.

No obstante, no puede soslayarse el hecho de que la elección haya sido impugnada, de que el Tribunal Electoral del Poder Judicial de la Federación tuviese que atender múltiples denuncias de los contendientes y señalara conductas ilegales, como fue la compra de tiempo en radio y televisión del Consejo Coordinador Empresarial para dañar al candidato de la izquierda, que si bien no fueron de una magnitud tal 
Esta revista forma parte del acervo de la Biblioteca Jurídica Virtual del Instituto de Investigaciones Jurídicas de la UNAM

que dieran lugar a que no se declarara válida la elección, sí contribuyeron a que el proceso electoral fuese visto con sospecha por franjas amplias de la población.

En ese ambiente poselectoral enrarecido, un grupo de académicos, intelectuales y periodistas hizo pública su postura en un desplegado que se tituló: La coexistencia de la pluralidad política reclama la defensa de las instituciones de nuestra democracia y cuyo texto íntegro es:

El 2 de julio millones de mexicanos fuimos a las urnas para elegir al Congreso de la Unión y al Presidente de la República. En diez estados hubo comicios locales: elegimos a tres gobernadores y al Jefe de Gobierno del Distrito Federal, con sus respetivos congresos locales y decenas de ayuntamientos.

Fueron elecciones auténticas entre partidos y candidatos plurales. Ninguna fuerza política ganó todo y ninguna perdió todo. Nuestra votación nos obliga a vivir y convivir en la pluralidad.

La convivencia y la competencia política civilizadas son el principio y el fin de la democracia. Este es el valor que hoy deseamos refrendar, preocupados por un clima público que puede erosionar lo que tanto trabajo ha costado construir.

Quienes firmamos este documento hemos votado por diferentes candidatos y partidos, pero nos unen las siguientes convicciones que creemos son la base para una coexistencia de la diversidad política tolerante y productiva:

1. Todas las fuerzas que participaron en la elección son legítimas. Expresan las propuestas y esperanzas de diferentes franjas de la sociedad. Esa diversidad es una riqueza que debe preservarse. Las elecciones son el único método que garantiza que sean los ciudadanos los que decidan quiénes deben gobernar y legislar.

2. Durante las campañas sobraron descalificaciones, pero la jornada del 2 de julio fue ejemplar por la participación ordenada de más de 42 millones de votantes. Fueron instaladas prácticamente todas las casillas por más de 500 mil ciudadanos sorteados y capacitados por el IFE. Todo ello transcurrió con normalidad. Reconocemos al IFE, más allá de errores puntuales, por su eficacia en la organización de esta tarea gigantesca. Refrendamos nuestra confianza en su imparcialidad y en su independencia.

3. Hemos elegido un Congreso plural donde ningún partido tendrá mayoría absoluta de votos; habrá gobernadores de diferentes partidos, congresos locales y ayuntamientos habitados por la variedad de las opcio- 
Esta revista forma parte del acervo de la Biblioteca Jurídica Virtual del Instituto de Investigaciones Jurídicas de la UNAM

nes políticas. Celebramos que la pluralidad política del país quedó genuinamente expresada en la elección del 2 de julio.

4. Las elecciones siguen probando que son el canal legítimo para la expresión de las más profundas inquietudes de una sociedad compleja como la mexicana. El espectacular crecimiento de la izquierda en estas elecciones confirma que es a través del sufragio como las distintas fuerzas políticas pueden expandir su influencia e insertar sus propuestas en la agenda nacional.

5. Existe, sin embargo, una aguda controversia en torno a la limpieza y validez de la elección presidencial. Quienes firmamos este documento hemos seguido los argumentos y pruebas presentadas en el litigio. No encontramos evidencias firmes que permitan sostener la existencia de un fraude maquinado en contra o a favor de alguno de los candidatos. En una elección que cuentan los ciudadanos puede haber errores e irregularidades, pero no fraude.

6. Los partidos y candidatos tienen el derecho de acudir al Tribunal Electoral del Poder Judicial de la Federación para hacer valer sus inconformidades. Esa es la ruta diseñada para atender dudas, quejas o conflictos electorales. No se pueden erradicar por completo los diferendos en materia electoral. Pero a lo largo de los últimos diez años todos ellos han sido resueltos a través de la vía jurisdiccional. Una vez que el Tribunal ha resuelto, se han terminado todos los conflictos.

7. No debemos alimentar una espiral de crispación y alarma. No inyectemos elementos que envenenen el ambiente político, no enfrentemos a los adversarios como si se tratara de enemigos. Edifiquemos un clima que refuerce la convivencia política en la diversidad.

8. Refrendamos nuestra confianza en el Tribunal Electoral. Es la última y definitiva voz autorizada para desahogar el diferendo en torno a la elección presidencial. No queda sino respetar la resolución del Tribunal.

9. Nuestras instituciones electorales son un patrimonio público que nadie debe lesionar. Son el soporte de una de las libertades fundamentales que los mexicanos hemos conseguido en estos años: la libertad de votar y ser votados sin que nadie manipule nuestro mandato. ${ }^{35}$

35 El desplegado, que apareció el 21 de agosto en el periódico Reforma, fue firmado por las siguientes personas: Adrián Acosta Silva, Larissa Adler-Lomnitz, Luis Miguel Aguilar, Héctor Aguilar Camín, José Antonio Aguilar Rivera, Sealtiel Alatriste, Eliseo Alberto, Jorge Alcocer, Enrique Alduncin, Ignacio Almada, Asunción Álvarez, Francisco Javier Aparicio, Antonella Attili, Ana Barahona, Roger Bartra, Eduardo Barzana, Ricardo Becerra, Humberto Beck, Ulises Beltrán, Edmundo Berumen, José Joaquín Blanco, Ed- 
Esta revista forma parte del acervo de la Biblioteca Jurídica Virtual del Instituto de Investigaciones Jurídicas de la UNAM

Finalmente, el Tribunal Electoral del Poder Judicial de la Federación declaró válida la elección y fue necesaria una vasta operación política para que los partidos, una vez más, fueran capaces de llegar a consensos para fortalecer la vía electoral.

La observación electoral en 2006 involucró a 25321 observadores individuales y a 179 agrupaciones; de ellos, 26 agrupaciones y 15675 observadores accedieron al fondo de recursos que en esa ocasión alcanzó los 40 millones de pesos. Como se puede ver, una vez más, se registró un descenso en la observación electoral frente a procesos previos.

Como señala el IFE en la Memoria del proceso electoral 2005-2006, ${ }^{36}$ "la jornada electoral del 2 de julio fue vigilada por 1992 consejeros electorales locales y distritales, 393126 representantes de partidos políticos ante mesas directivas de casilla, 25321 observadores elec-

mundo Calva, Salvador Camarena, Enrique Canales, Julia Carabias, Emmanuel Carballo, Miguel Carbonell, María Amparo Casar, Jorge G. Castañeda, Marina Castañeda, Adolfo Castañón, Ricardo Cayuela, Santiago Corcuera Cabezut, Lorenzo Córdova, Ramón Cota Meza, Israel Covarrubias, José Luis Cuevas, Leonardo Curzio, Luis de la Barreda Solórzano, José Antonio de la Peña, Germán Dehesa, Roberto Diego Ortega, Christopher Domínguez Michael, Denise Dresser, Irene Durante Montiel, Juan Eibenschutz, Roberto Eibenschutz, Ricardo Elías, Álvaro Enrigue, Fernando Escalante Gonzalbo, Beatriz Espejo, Guillermo Fadanelli, Fátima Fernández Christlieb, Jorge Fernández Meléndez, Héctor Fix-Zamudio, Enrique Florescano, Fernando García Ramírez, Luis Emilio Giménez Cacho, David Gómez-Álvarez, Luis González de Alba, José Antonio González de León, Olbeth Hansberg, Carlos Heredia, Claudio Isaac, Ángel Jaramillo, Fuad Juan, Gerardo Kleinburg, Enrique Krauze, León Krauze, Mario Lavista, Soledad Loaeza, Cassio Luiselli, Ángeles Mastretta, Álvaro Matute, Samuel Melendrez Luévano, Víctor Manuel Mendiola, Mauricio Merino, Jean Meyer, Pedro Meyer, Mario J. Molina, Silvia Molina, Ciro Murayama, Humberto Murrieta, Benito Nacif, Enrique Norten, Octavio Novaro, Federico Novelo, Joel Ortega Juárez, Antonio Ortiz Mena López Negrete, Pablo Ortiz Monasterio, Ignacio Padilla, Guillermo Palacios y Olivares, Pedro Ángel Palou, David Pantoja Morán, Julio Patán, Braulio Peralta, Rafael Pérez Gay, Rafael Pérez Pascual, Jacqueline Peschard, Ernesto Piedras, Jean-Francois Prud'homme, Ricardo Raphael, Román Revueltas Retes, Federico Reyes Heroles, Jorge Javier Romero, Alejandro Rossi, Luis Rubio, Pablo Rudomín, Daniel Sada, Luis Salazar, Pedro Salazar Ugarte, Hortensia Santiago, José Sarukhán, Cecilia Sayeg, Guillermo Sheridan, Isabel Silva Romero, Carlos Sirvent, Guillermo Soberón, Fernanda Solórzano, Beatriz Solís Leree, Jaime Tamayo, Ricardo Tapia, Carlos Tello Díaz, Raúl Trejo Delarbre, Julio Trujillo, Isabel Turrent, Guillermo Valdés Castellano, Eduardo Valle, Josefina Zoraida Vásquez, Rodolfo Vázquez, Xavier Velasco, Diego Villaseñor, José Warman, José Woldenberg, Ramón Xirau, Gina Zabludovsky, Fernando Zertuche, Leo Zuckermann.

36 Instituto Federal Electoral, Memoria del proceso electoral federal 2005-2006, México, IFE, 2007. 
torales y 693 visitantes extranjeros". El apunte es relevante porque, a diferencia de lo que ocurre en otros países, en México desde inicio de los años noventa se diseñó normativamente un sistema de acompañamiento ciudadano a la organización de la elección que asegura mecanismos de transparencia y vigilancia que no ocurren en otros contextos. Por ejemplo, los consejeros electorales son seis ciudadanos independientes, que se incorporan a cada uno de los 300 consejos distritales federales y a los consejos locales de cada una de las 32 entidades federativas. Son esos ciudadanos, con sus votos, quienes van tomando las decisiones a lo largo del proceso electoral. Asimismo, como se mencionó antes, las casillas electorales son instaladas, operadas y cerradas por ciudadanos que son insaculados (a partir de un sorteo que combina tanto el mes de nacimiento como la primera letra del apellido paterno) y capacitados para tal efecto. Las elecciones en México, de esta forma, si bien son organizadas por una institución del Estado, autónoma, como es el IFE, son operadas por ciudadanos que no sólo observan sino que toman decisiones, identifican a sus vecinos a la hora de emitir el sufragio, cuentan los votos y llenan las actas de escrutinio que dan sustento legal a la elección.

Un tema que se ha vuelto cada vez más sensible en los procesos electorales de México se refiere a las condiciones de la competencia, es decir, a los recursos de que disponen los partidos para llegar al electorado, así como a la participación de terceros actores - gobiernos federal y locales, grupos empresariales, poderes mediáticos, etcétera- en las campañas proselitistas que, eventualmente, pueden influir en los votantes alterando el principio general de equidad entre partidos y candidatos que debe estar presente en la contienda política para que sea genuinamente democrática.

En buena medida, la reforma electoral de 2007-2008 fue la respuesta a las inquietudes que se habían planteado sobre la credibilidad y calidad de los procesos electorales en México.

Con la reforma electoral de 2007-2008 (el primer año se aprobaron por el Constituyente permanente las modificaciones a la Constitución $y$, el segundo, entraron en vigor los cambios al Código Federal de Instituciones y Procedimientos Electorales, Cofipe), se introdujeron adecuaciones puntuales pero sustantivas al diseño general de 1996: a) la fórmula para calcular el monto total de financiamiento público a los partidos se hizo más simple al tiempo que se restringieron los volúmenes de recursos públicos para las campañas electorales federales; 
Esta revista forma parte del acervo de la Biblioteca Jurídica Virtual del Instituto de Investigaciones Jurídicas de la UNAM

b) se acotó el total de financiamiento privado al que pueden acceder los partidos; $c$ ) se refrendaron los vetos de aportaciones de determinados actores a las campañas, y se elevó a rango constitucional la prohibición para hacer aportaciones en especie a los partidos a través de campañas pagadas por terceros en radio y televisión; $d$ ) se prohibió el gasto de los partidos en los medios electrónicos y disminuyeron, en consecuencia, los topes de gasto de las campañas, y e) se fortalecieron las capacidades fiscalizadoras de la autoridad electoral y se creó un cuerpo especializado en la materia.

El encarecimiento de las campañas electorales por el costo del acceso a los medios electrónicos, la intervención en la etapa proselitista de terceros para alterar las condiciones de la competencia, así como las dificultades para fiscalizar las ingentes cantidades de recursos que se venían canalizando a radio y televisión durante las contiendas políticas, hicieron necesaria una amplia operación política para acotar el poder del dinero y de los medios electrónicos. Ese es, sin duda, el rasgo más significativo de la reforma constitucional de 2007.

El modelo mexicano de regulación de las condiciones de la competencia, así, se distancia de los sistemas más "liberales" como el de Estados Unidos, caracterizados por la permisividad al gasto privado - a través de los llamados "gastos independientes" a los partidos-, la ausencia de restricciones a la inyección de dinero a las campañas por parte de particulares - y en especial de las grandes corporaciones económicas-, así como por una débil fiscalización sobre los ingresos y egresos de los partidos políticos.

En nuestro caso, a partir de la reforma electoral de 2007 se prohíbe desde la Constitución la compra de espacios y tiempos en radio y televisión para difundir los mensajes de los partidos y se establece que la presencia de partidos y candidatos en radio y televisión será sólo a través de los tiempos oficiales del Estado, que en esta materia gestiona el Instituto Federal Electoral. Además, el IFE tiene facultades para sancionar, mediante procedimientos expeditos, las violaciones que se cometan; incluyendo la posibilidad de suspender de manera inmediata, las transmisiones radiofónicas o televisivas que transgredan esas prohibiciones. Asimismo, se elevó a rango constitucional la prohibición para que terceros adquieran publicidad en los medios electrónicos para favorecer o afectar a algún partido o candidato. Una disposición adicional es que se prohíbe la personalización —mediante la utilización de la imagen o la voz de los titulares de los entes públi- 
cos- de la publicidad que difundan los órganos del Estado, la cual deberá tener carácter institucional y fines informativos, educativos y de orientación social.

De esta forma, en vez de dejar espacio para que quienes tienen poderío económico y capacidad de compra de publicidad puedan afectar la equidad de la contienda, se pone énfasis en que las campañas son un asunto de interés público y ha de velarse porque se desarrollen en condiciones adecuadas. Por otra parte, una vez que se restringieron los gastos de los partidos, se procedió a disminuir su financiamiento, en especial, el que venían recibiendo para gastos de campaña.

A partir de la reforma constitucional, el financiamiento público de los partidos políticos depende de dos variables previamente no consideradas a nivel federal: el tamaño del padrón electoral y el salario mínimo vigente. El inciso a, párrafo segundo, del artículo 41 constitucional, establece acerca del financiamiento ordinario que "se fijará anualmente, multiplicando el número total de ciudadanos inscritos en el padrón electoral por el $65 \%$ del salario mínimo diario vigente en el Distrito Federal".

La reforma constitucional determina (inciso $b$, párrafo II del artículo 41 constitucional) que:

El financiamiento público para las actividades tendientes a la obtención del voto durante el año en que se elijan presidente de la República, senadores y diputados federales, equivaldrá al 50\% del financiamiento público que le corresponda a cada partido político por actividades ordinarias en ese mismo año; cuando sólo se elijan diputados federales equivaldrá al $30 \%$ de dicho financiamiento por actividades ordinarias.

El cambio es importante porque, para empezar, se diferencian elecciones donde se renueva la presidencia y todo el Congreso de la Unión de las llamadas “intermedias". La fórmula que se aplicaba desde 1996 estipulaba que en año electoral, sin distingos, se duplicaría el financiamiento ordinario, lo cual dio lugar a que en las elecciones intermedias algunos partidos recibieran más financiamiento público para campañas del que podían gastar en actividades proselitistas (en 2003, para señalar el caso más extremo, PAN, PRI y PRD obtuvieron en conjunto más de 870 millones para gasto en campaña por encima de los topes de gasto de ese año). E incluso, en 2003, donde sólo se renovó la Cámara de Diputados, los partidos recibieron más recursos 
Esta revista forma parte del acervo de la Biblioteca Jurídica Virtual del Instituto de Investigaciones Jurídicas de la UNAM

en un $41.7 \%$, en términos reales, que los que obtuvieron para las campañas del año 2000.

La nueva redacción constitucional permitió disminuir los recursos entregados a los partidos en años electorales. Los críticos a la reforma constitucional señalan que, al reducirse los gastos en medios y acortarse las campañas, los partidos en realidad no pierden tanto. Pero el objetivo de la reforma fue abaratar las campañas, mas no empobrecer a los partidos políticos. Cabe recordar que no hay democracia estable sin partidos sólidos.

En lo que toca al financiamiento de particulares a la política se acota aún más la parte proveniente de fuentes privadas: sólo podrá ser del $10 \%$ del tope de gasto de la campaña presidencial previa.

En materia de fiscalización, desde la carta magna se define que los secretos bancario, fiduciario y fiscal, que en el pasado entorpecieron las averiguaciones del IFE, no le serán oponibles a la autoridad electoral cuando fiscalice los recursos involucrados en la contienda electoral.

En suma, el modelo de regulación de las condiciones de la competencia en México vuelve a poner en el centro la equidad en la contienda. Ese fue el pacto político que permitió ir trascendiendo la confrontación electoral de 2006.

En 2009, el IFE renovado (seis de sus nueve consejeros electorales, incluyendo al consejero presidente, fueron sustituidos a partir de la reforma de 2007-2008), organizó las elecciones intermedias con las que se eligió la nueva composición de la Cámara de Diputados. Una vez más, como venía ocurriendo desde 1997, ningún partido político alcanzó la mayoría de votos, de tal suerte que inició la quinta legislatura de gobierno dividido, donde toda iniciativa tuvo que ser respaldada por, al menos, dos de los tres grandes partidos políticos nacionales.

\section{2012: segunda alternancia y la confirmación de la pluralidad política}

En 2012, con un nuevo marco legal, se celebraron elecciones federales en las que se renovó el Congreso de la Unión y se eligió presidente de la República; además, hubo elecciones locales en quince entidades federativas del país. 
La participación electoral rebasó los 50 millones de ciudadanos. Los resultados son más que ilustrativos del asentamiento de la pluralidad.

Al PAN, tras haber logrado la primera alternancia en la Presidencia de la República en siete décadas (año 2000) y de gobernar al país por doce años, los ciudadanos le dieron la espalda y lo colocaron en un contundente tercer lugar. Se trata de una reprobación inequívoca de la manera de gobernar, del rumbo de las políticas, de un desencuentro de los electores con las prioridades del PAN. La ola de violencia que azotó al país sin que el presidente Calderón y su equipo mostraran la sensibilidad necesaria hacia las víctimas y respecto al temor extendido en la población, así como los magros resultados en materia de bienestar — no sólo para los asalariados y trabajadores, sino para el empresariado mismo-, son elementos para explicar por qué tres de cada cuatro mexicanos decidieron evitar un nuevo gobierno de Acción Nacional. El PAN perdió además la entidad más importante que gobernaba (Jalisco), yéndose también al tercer lugar como le ocurrió en Morelos. Apenas conservó Guanajuato. De los tres grandes partidos de México, el PAN, el partido en el gobierno, fue el más castigado en las urnas en 2012.

El Partido Revolucionario Institucional obtuvo más votos que sus adversarios, rebasando el 38\% de los sufragios depositados en la elección presidencial. Pero fue un porcentaje apenas $2 \%$ mayor al que alcanzó el derrotado Francisco Labastida en 2000 (36.1\%) y muy inferior al de Zedillo en 1994 (48.69\%). Nunca un candidato priista ganador a la presidencia había recibido tan bajo porcentaje de votos. Pero lo más importante es que el PRI no consiguió por sí mismo la mayoría en el Congreso. Enrique Peña Nieto solicitó una y otra vez contar con mayoría en las Cámaras de Diputados y Senadores para tener un "gobierno eficaz", la gente no se lo concedió, al contrario, se enfrenta a una Cámara baja donde incluso aliándose con el PVEM y el PANAL no asegura el 50\% más uno de los votos, y a un Senado donde toda iniciativa tendrá que contar con el aval del PAN o de los partidos de la izquierda. Zedillo, el único presidente priista que experimentó un gobierno dividido de 1997 a 2000, tuvo el control del Senado; Peña no: es el mandatario surgido del PRI más acotado de la historia.

La coalición de izquierdas que encabezó el Partido de la Revolución Democrática se colocó como segunda fuerza política nacional, desplazando a la derecha al tercer lugar. Ganó, además, dos entidades en las que nunca había gobernado: Tabasco y Morelos. En el Distrito 
Esta revista forma parte del acervo de la Biblioteca Jurídica Virtual del Instituto de Investigaciones Jurídicas de la UNAM

Federal, tras quince años ininterrumpidos de gobiernos, la izquierda obtuvo su mejor resultado. Miguel Ángel Mancera recibió más de tres millones de sufragios de los capitalinos (64\% del total), y la coalición que lo apoyó cuenta con una cómoda mayoría en la Asamblea Legislativa del Distrito Federal, además de que conquistó la delegación Miguel Hidalgo que tradicionalmente había votado por el PAN. Ahora bien, en los votos por la izquierda en el DF hay un dato revelador, 493000 capitalinos que votaron por Mancera no lo hicieron por el candidato presidencial Andrés Manuel López Obrador (quien recibió 2.5 millones de votos de la capital, una sexta parte de todos los que obtuvo en el país). En la entidad con mayor presencia de la coalición de izquierda hubo electores que siendo votantes de izquierda no respaldaron a López Obrador.

Alternancia, equilibrio de poder, gobiernos divididos, castigo y premio con el sufragio, fueron los rasgos dominantes de los resultados electorales de 2012. Conviene preguntarse si esos fenómenos, propiamente democráticos, podrían producirse en elecciones que no hayan sido genuinamente libres.

En materia de observación electoral, en 2012 se dispuso de un fondo de recursos aportados por el IFE de treinta y seis millones ochocientos mil pesos y una cantidad similar aportada por la Secretaría de Gobernación. Ese año, operó el Fondo de Apoyo para la Observación Electoral 2012, un programa de financiamiento y asistencia técnica a observadores electorales, con la concurrencia del Programa de Naciones Unidas para el Desarrollo (PNUD), el IFE y el Tribunal Electoral del Poder Judicial de la Federación.

El Fondo de Apoyo a la Observación Electoral 2012 convocó a organizaciones de la sociedad civil a participar en las observaciones, de las cuales 86 concursaron y fueron seleccionadas 44 . Los temas de la observación realizada por dichas organizaciones fueron: voto joven, 4; voto indígena, 8; participación ciudadana, 11; género, 12; legalidad electoral, 15; medio ambiente, 1, y derechos humanos, 1.

El Fondo de Apoyo a la Observación Electoral 2012 también convocó a centros de investigación a participar en la observación, concursando 22 y siendo seleccionados 11. Los temas de observación fueron: administración de tiempos del Estado en radio y televisión, 3; libertad 
Esta revista forma parte del acervo de la Biblioteca Jurídica Virtual del Instituto de Investigaciones Jurídicas de la UNAM

de expresión, 4; fiscalización de los recursos financieros de los partidos políticos, 1 ; justicia electoral, $3 .^{37}$

Asimismo, se convocó a dos organizaciones extranjeras a realizar la observación, el Centro Carter, con el tema de confianza en el sistema electoral, e IFES, sobre fiscalización de los recursos de los partidos políticos.

Como se ve, más que una observación sobre el proceso de votación el día de la jornada electoral, tal como ocurrió a lo largo de los primeros ejercicios de observación, en la experiencia reciente los temas se han movido hacia indicadores de la calidad y equidad del proceso electoral en su conjunto. Sobresale la importancia de los temas ligados con las condiciones de la competencia electoral, en especial los del dinero y fiscalización de los recursos, así como el acceso de los partidos políticos a los medios de comunicación.

Lo anterior no es casual, la tensión entre dinero y política y el papel de los medios en los procesos políticos son consustanciales a la vida democrática contemporánea.

\section{Los temas de la democracia, no de la transición}

La competencia democrática en las sociedades complejas reclama una enorme movilización de recursos. Los partidos políticos deben mantener amplias estructuras de militantes para presentar candidatos, para asegurar su presencia a lo largo y ancho del territorio, para acercarse a los ciudadanos, además, requieren estar presentes en los medios de comunicación pues, como ha señalado Raúl Trejo "no hay política de masas (es decir, política moderna), sin medios de comunicación", ${ }^{38}$ en época de elecciones - pero no sólo en ella- partido o candidato que esté fuera de las ondas de la radio o de la pantalla televisiva acaba predicando en el desierto.

El incremento en los costos de la política en las democracias contemporáneas está determinado en buena medida por dos elementos complementarios: a) la evolución de los propios partidos hacia estruc-

${ }_{37}$ Programa de Naciones Unidas para el Desarrollo, Fondo para la Observación Electoral, 2012, Primer Informe, México, PNUD, 2012 b.

38 Trejo Delarbre, Raúl, Mediocracia sin mediaciones, México, Cal y Arena, 2001. 
Esta revista forma parte del acervo de la Biblioteca Jurídica Virtual del Instituto de Investigaciones Jurídicas de la UNAM

turas nacionales abarcadoras, incluyentes, que rebasan los límites del "partido de clase" para convertirse en lo que Angelo Panebianco ha llamado "partido profesional-electoral", ${ }^{39}$ por lo que requieren sostener su estructura con volúmenes de recursos que trascienden las donaciones de simpatizantes y militantes, y $b$ ) la necesidad de los partidos de garantizar su presencia en los medios de comunicación masiva.

Frente a esta ingente necesidad de dinero que encaran los partidos, resulta adecuado alejarse de visiones ingenuas sobre el asunto. Ocurre en cualquier mercado, siempre que exista una demanda en la cual se pueda encontrar contraprestación, habrá la oferta correspondiente - que es una proposición inversa a la conocida Ley de Say que señala que "toda oferta genera su propia demanda"-. En otras palabras, siempre que alguien demanda un bien o servicio y está dispuesto a pagar por él, habrá un oferente presto a surtirlo (este proceso se presenta incluso en mercados de bienes ilegales, como es el caso de las drogas, cuya oferta no ceja de ampliarse al ritmo que crece la demanda, y ello sucede con independencia de las barreras legales que se le impongan o guerras policiales que se le declaren al comercio de psicotrópicos). En política, entonces, siempre que los partidos requieran dinero, habrá quien lo ofrezca $-\mathrm{y}$, claro, lo cobre más adelante a través de conseguir dividendos que arrojen las decisiones del partido o del político beneficiado una vez que esté en el gobierno-. Siendo así, mientras los partidos tengan la necesidad de hacerse de dinero, habrá recursos de algún lado. Dinero y política están, entonces, en una relación complicada y permanente que es consustancial a la existencia de la celebración de contiendas políticas abiertas, se trata de una tensión estructural e inevitable de la vida democrática.

Pero reconocer que el dinero es indispensable para la actividad política en las sociedades de nuestros días, y subrayar que la influencia del poder económico puede tener efectos perniciosos (de hecho los ha tenido en múltiples ejemplos internacionales) sobre la competencia propiamente democrática - esa que concede igual peso a todos los ciudadanos para influir en las decisiones públicas y no los discrimina en función, por ejemplo, de su riqueza patrimonial- no implica (o no debería implicar) asumir sin más que poderoso caballero es Don Dinero y dar por válida la idea de que la lógica del mercado - que en su naturaleza conlleva a la concentración de poder- debe imponerse y

39 Panebianco, Angelo, Modelos de partido, Madrid, Alianza, 1995. 
ser el fiel de la balanza en la política. Como ha observado el catedrático español y novelista José Luis Sampedro: "Una cosa es estar de acuerdo con una economía de mercado y otra desear una sociedad de mercado".

$\mathrm{Al}$ asumir que el dinero gravita sobre las contiendas electorales y que contribuye a definir el perfil del sistema político y la calidad de la democracia, prácticamente todos los países democráticos se han abocado a definir normas para favorecer la transparencia y la legalidad en el origen de los recursos que van a la política, así como a garantizar la independencia de los propios partidos políticos frente a grupos de poder económico o, peor aún, delincuencial. Se busca, así, inducir una competencia política civilizada y democrática, donde no prive la ley del más fuerte o del más rico. Las normas, por supuesto, no suponen soluciones inmediatas ni permanentes a los problemas que genera la influencia del dinero sobre la contienda política, ni niegan el hecho de que la lucha por el poder la protagonizan seres humanos cargados de intereses y no arcángeles que nunca caerán en tentación, pero como ha señalado Francisco Laporta ${ }^{40}$ "nadie niega que la enfermedad es algo que se da y se dará, en un grado u otro, en todas las sociedades; pero a nadie se le ha ocurrido tampoco pensar que esto sea un argumento para que debamos aceptarla o dejar de luchar contra ella”.

El tema del dinero en la política y el acceso a los medios es tan relevante para la vida mexicana que fue recogido en uno de los apartados del Pacto por México que signaron el 2 de diciembre de 2012 el presidente constitucional Enrique Peña Nieto y los presidentes de los tres principales partidos del país. El apartado 5.3 del Pacto, titulado Partidos Políticos y Elecciones dice a la letra:

Los partidos políticos requieren de un marco jurídico que genere mayor certidumbre, transparencia y estabilidad al sistema político en su conjunto. De igual forma, los procesos electorales tienen que ser más baratos y más transparentes. Para lograr estos objetivos, se impulsarán las siguientes acciones:

- Se aprobará una Ley General de Partidos para dar un marco jurídico estable y claro a la actuación de los mismos tanto en tiempos electorales como en tiempos no electorales (Compromiso 89).

${ }^{40}$ Laporta, Francisco, "La corrupción política: introducción general", en Laporta, Francisco y Álvarez, Silvina (comps.), La corrupción política, Madrid, Alianza, 1997. 
Esta revista forma parte del acervo de la Biblioteca Jurídica Virtual del Instituto de Investigaciones Jurídicas de la UNAM

- Se impulsará una Reforma Electoral que atienda los siguientes temas (Compromiso 90).

- Reducción y mayor transparencia del gasto de los partidos.

- Disminución en el monto de los topes de campaña.

- (Incorporación a las causales de nulidad de una elección lo siguiente: 1) el rebase de los topes de campaña; 2) la utilización de recursos al margen de las normas que establezca el órgano electoral; y 3) la compra de cobertura informativa en cualquiera de sus modalidades periodísticas, con la correspondiente sanción al medio de que se trate).

- Revisión de los tiempos oficiales de radio y televisión para impulsar una cultura de debate político y una racionalización del uso de los anuncios publicitarios.

- Prohibir el uso y la entrega de utilitarios de promoción electoral, tales como materiales plásticos, materiales textiles, despensas y materiales de construcción.

- Fortalecer la legislación para evitar el uso de esquemas financieros y/o recursos de origen ilícito con el propósito de inducir y coaccionar el voto.

- Crear una autoridad electoral de carácter nacional y una legislación única, que se encargue tanto de las elecciones federales, como de las estatales y municipales.

\section{A modo de conclusión}

A lo largo de este ensayo se ha visto cómo México logró transitar en las últimas dos décadas del siglo XX de un sistema de partido hegemónico a un régimen plural de partidos políticos. Asimismo, ha edificado una institucionalidad y normatividad electoral que combinan el profesionalismo técnico de una institución autónoma, el Instituto Federal Electoral, con una amplia participación ciudadana en las tareas de organización y ejecución de las elecciones. En este periodo, la observación electoral se ha modificado, por una parte ha caído la participación cuantitativa de observadores, y por otro lado los temas se han movido de la vigilancia del respeto al voto, de los asuntos procedimentales al de las condiciones de la competencia.

Más que de una agenda de observación electoral, se ha abierto una agenda de investigación sobre la democracia, pues incluso la "obser- 
Esta revista forma parte del acervo de la Biblioteca Jurídica Virtual del Instituto de Investigaciones Jurídicas de la UNAM

vación" en 2012 fue con frecuencia investigación de organismos especializados en dicha tarea.

Así, si la observación electoral se ha modificado sustancialmente, podría ser momento para plantear si esa labor, tradicionalmente realizada por ONG's y agrupaciones de la sociedad civil, debe seguir recibiendo recursos públicos del Estado para tener sentido.

\section{Fuentes consultadas}

Aguilar Camín, Héctor, Después del milagro, México, Cal y Arena, 1991.

Becerra, Ricardo et al., La mecánica del cambio político en México, México, Cal y Arena, 2000.

Castellanos, Laura, México armado, 1943-1981, México, Era, 2007.

Cordera, Rolando, Crónicas de la adversidad, México, Cal y Arena, 1999.

Córdova, Arnaldo, La política de masas del cardenismo, México, Era, 1974.

Córdova, Lorenzo y Murayama, Ciro, Elecciones, dinero y corrupción. Pemexgate y Amigos de Fox, México, Cal y arena, 2006.

instituto de Estudios para la Transición Democrática, A. C. (IETD), Para una transición democrática, México, IETD, mimeo, 1989.

Instituto Federal Electoral, Memoria del proceso electoral federal 2000, México, IFE, 2001.

- - , Memoria del proceso electoral federal 2005-2006, México, IFE, 2007.

LAPORTA, Francisco, "La corrupción política: introducción general", en Laporta, Francisco y Álvarez, Silvina (comps.), La corrupción política, Madrid, Alianza Editorial, 1997.

Moreno-Brid, Juan Carlos y Ros, Jaime, Desarrollo y crecimiento en la economía mexicana. Una perspectiva histórica, México, Fondo de Cultura Económica, 2011.

Murayama, Ciro, La economía política de la educación superior, México, ANUIES, 2009.

Pascual Moncayo, Pablo, Las elecciones de 1994, México, Cal y Arena, 1995. 
Esta revista forma parte del acervo de la Biblioteca Jurídica Virtual del Instituto de Investigaciones Jurídicas de la UNAM

Programa de Naciones Unidas para el Desarrollo, Propuesta técnica de observación electoral, México, 2012.

_-_, Fondo para la Observación Electoral, 2012, Primer Informe, México, PNUD, 2012.

Rавотniкof, Nora, "Dos conceptos de sociedad civil”, en Salazar, L. (coord.), México 2000. Alternancia y transición a la democracia, México, Cal y Arena, 2001.

SARtori, Giovanni, Partidos y sistemas de partidos, Madrid, Alianza, 1980.

Trejo Delarbre, Raúl, Crónica del sindicalismo en México (19761988), México, Siglo XXI-UNAM, 1990.

-_-, Mediocracia sin mediaciones, México, Cal y Arena, 2001.

Woldenberg, José, Violencia y política, México, Cal y Arena, 1995. -_-, La transición democrática en México, México, El Colegio de México, 2012.

Paz, O., "Doble mandato", Vuelta, México, núm. 215, octubre de 1994. SalazAr, Luis, México 2000. Alternancia y transición a la democracia, Cal y Arena, México, 2001.

Panebianco, Angelo, Modelos de partido, Madrid, Alianza Editorial, 1995. 